\title{
Emission of Trace Gases from Paddy Blazing in North- Western States of India: A Review
}

\author{
D.O.I - 10.51201/Jusst12642 \\ http://doi.org/10.51201/Jusst12642
}

\section{Samanvya Singh ${ }^{1}$}

\author{
Nausha Shetty*Corresponding Author \\ ${ }^{1}$ Department of Civil Engineering, Manipal Institute of Technology, Manipal Academy of Higher \\ Education, Manipal India. \\ ${ }^{2}$ Department of Civil Engineering, Manipal Institute of Technology, Manipal Academy of Higher \\ Education, Manipal India. \\ ${ }^{4}$ Department of Civil Engineering, Manipal \\ Institute of Technology, Manipal Academy of Higher Education, Manipal India
}

\begin{abstract}
India being an Agricultural State with diverse crop culture. Various crops are scattered and harvested in every Rabi and Kharif season and farmers are very much dependent on these seasons as these seasons decide the quality of the crop. The modern equipment which a farmer uses is a Combined Harvesting Machine. Now the problem with this machine is that it cultivates the crop from a height of 1 meter from the ground which generates the leftover residual of rice on the ground. Due to the composition of farm leftover, its blazing is a little different in comparison to that of Grassland and forest fire. Farm residue burning emits a huge amount of harmful pollutants, such as $\mathrm{N}_{2} \mathrm{O}, \mathrm{CO}_{2}, \mathrm{CH}_{4}$, $\mathrm{CO}, \mathrm{NH}_{3}, \mathrm{SO}_{2}, \mathrm{NO}_{\mathrm{x}}, \mathrm{HC}$ 's, VOC's, and SPM.

These emitting pollutants cause harmful impacts to Humans, Plants, and Animals. Focusing on the influence on humans these pollutants can cause pneumoconiosis, acute bronchitis, skin allergies, irritation to the eyes, blindness, scarred cornea, and formation of cataracts.
\end{abstract}

Keywords: thermal power plant; ash pond; atomic absorptive spectrometry; soil digestion; heavy metal; tri-acids;

\section{Introduction}

The main reason for this practice is the short duration left after the cultivation of rice and the farmers get a very short span of the time period for the distribution of the seed of wheat crop and the machine leaves the residual after harvesting. Therefore the best option a farmer is left out is flaming of that residue left on the ground. Almost all the farmers in the states of Punjab and Haryana set their fields on fire as a result huge smoke forms in the state. Now, this smoke does not remain in those specific areas because of the wind direction and as a result of this practice, smoke is seen in Delhi and nearby places which include Noida, the National Capital Region (NCR), and some parts of Uttar Pradesh In India, The National Green Tribunal is an agency that takes this practice of paddy azing very seriously and take strict action against the states. Government associations and exploration focuses are empowering substitute use of straw and paddy instead of blasting, for example, utilizing ranch buildup as creature grub and bed linen material in steers scrap, for use in mushroom breeding, for an alternative feed in nuclear energy stations, for use as a bio-oil. In the last twenty years, many other processes are developed which brings different lternatives of biofuels from the residue remaining of the crop such as prill, logs, charcoal which can be used in house boilers, stoves. In this article, an attempt is made over the study of paddy blazing in the north-western districts of Punjab and Haryana and methods which help to use the crop residue as an alternative source of energy. 


\section{Literature review and methodology}

\subsection{Study area}

Anu Rani Sharma, Sailesh Kumar Kharol, K.V.S. Badrinath, and Darshan Singh,(2009) ${ }^{[1]}$ this paper describes the effect of agricultural crop residue burning on the properties of aerosol over the state Haryana and Punjab in the period of October 2006 and 2007. Crop residue of rice is blazed during this period in the region of Indo-Gangetic Plains (IGP) this practice leads to notable influence on aerosol loading and along with greenhouse gas emissions. IGP covers $22 \%$ of the land and around $42 \%$ of all food grains generation. In the study methods adopted are:

I. Multi-Wavelength Radiometer (MWR)- This instrument measures the shadow destruction of ground coming fluctuation as a derivative of the solar altitude edge at ten wavelengths ranging between 380 to $1025 \mathrm{~nm}$.

II. MODIS Aerosol Optical Depth (AOD)- Moderate Resolution Imaging Spectrometer (MODIS) enquires regularly in different bands of detectable to thermal infrared.

III. OMI Aerosol Index- Aerosol Index values from the Ozone Monitoring Instrument (OMI) are used. AI is defined as the residual compared to measured light and measured using the assumption of the Lambart Equal Reflectivity (LER).

IV. OMI tropospheric $\mathrm{NO}_{2}-\mathrm{OMI} / \mathrm{AURA} \mathrm{NO}_{2}$ total and stratosphere list L2 (V00) global product from GES-DISC (http://gdata1.sci.gsfc.nasa.gov/daac- bin/G3.gui.cgi?instance_id=omil2g) at 0.25 deg spatial resolution were considered in the study.

V. Calipso- The Cloud-Aerosol Lidar and Infrared Path finder Satellite Observation (CALISPO) provide an estimation of clouds and airborne particles in controlling the climate of the earth and air aspect.

VI. MOPITT CO- Carbon monoxides Measurements of pollution in the troposphere instrument (MOPITT) is used to measure the Carbon monoxide variations in crop slag blazing. It is a snug based-viewing gas relation radiometer and gives $\mathrm{CO}$ emissions around 22 kmhorizontally.

VII. MODIS Active fire locations - Observations of burning in a day is observed four times from the Terra and Aqua satellites.

In the current investigation, the effect of farming harvest buildup consumption on vaporized properties during the period between October 2006 and 2007 a long span of time over the state of Punjab was dissected. Aftereffects of investigation recommended that: More estimations of AOD500 displayed during crop buildup consuming tenure proposing expanded fixation of amassing mode molecule in the air with increased turbidity circumstances. The AOD esteems were increased by $21 \%$ during the month October 2007 as compared to October 2006 and paddy blazing was credited for this reason.

Satellite-inferred perceptions on AOD, vaporized list (Artificial intelligence), NO2 and carbon monoxide (CO) indicated essentially increment in the month of October 2007 in comparison to October 2006 corresponding to ground perceptions of vaporized boundaries.

Evaluations on vaporized condensed wave radiate driving proposed expanded barometrical assimilation of radiation during crop buildup consuming period over the locale.

Hefeng Zhang, Dawei Hu, Jianmin Chen, Xingnan Ye, (2011) ${ }^{[2]}$ describes the measurements and determination of different PAH's from the emission caused by the blazing of rice, wheat, and corn crop residue in China. PAHs are common natural pollutants and are largely side products of deficient burning of biomass. The measurement of PAH is done by an instrument called WPS (Wide- Range Spectrometer). PAHs are present in both the Suspended Phase and Gaseous Phase and they are collected simultaneously and analyzed by GC-MS. 
For the above-mentioned three crops, different accumulation peaks were noticed. For Rice, Wheat, and Corn the peaks were $0.10,0.15$, and $0.15 \mu \mathrm{m}$ respectively. For each horticultural harvest buildup, five equal consumers were directed. Before each test, foundation particles and the number of hydrocarbons were estimated. In the investigation time frames, foundation temperature and RH were somewhere in the range of 26 and $29{ }^{\circ} \mathrm{C}$ and 55 what's more, 69\%, separately. In the wake of consumption, the unburned straws and debris were gathered for gauging.

Figure -1: Geological circulation showing the density of Emissions in China.

(Units: $\mathrm{g} \mathrm{km}^{-2}$ )

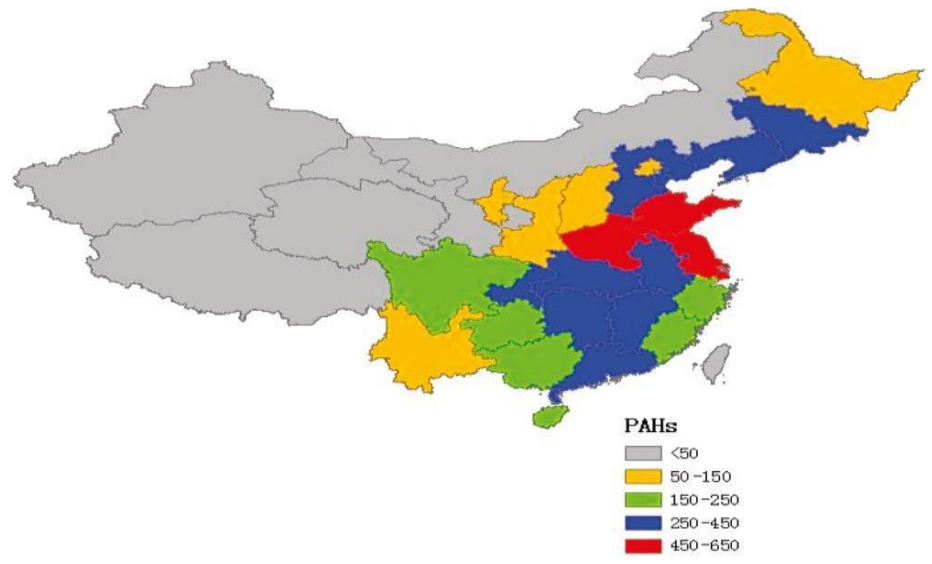

Table-1: Radiation Factors of PAHs from straw burning of Rice, Wheat, and Corn (Units: $\mathrm{mg} \mathrm{kg}^{-1}$ )

\begin{tabular}{|c|c|c|c|c|c|c|}
\hline \multirow[t]{2}{*}{ PAHs } & \multicolumn{2}{|l|}{ Rice } & \multicolumn{2}{|l|}{ Corn } & \multicolumn{2}{|l|}{ Wheat } \\
\hline & Particle & Gas & Particle & Gas & Particle & Gas \\
\hline Naphthalene & 0.03 & 1.77 & j & 0.43 & V & 0.28 \\
\hline Acenaphthylene & 0.04 & 0.87 & 0.02 & 0.3 & 0.04 & V \\
\hline Acenaphthene & 0.06 & 0.09 & 0.10 & 0.05 & 0.16 & 0.13 \\
\hline Fluorene & 0.02 & 0.07 & 0.05 & 0.03 & 0.03 & 0.04 \\
\hline Anthracene & 0.02 & 0.39 & 0.18 & 0.05 & 0.08 & t \\
\hline Phenanthrene & 0.03 & 0.12 & 0.08 & 0.02 & 0.07 & 0.03 \\
\hline Fluoranthene & 0.29 & 0.10 & 0.19 & 0.02 & 0.16 & 0.03 \\
\hline Pyrene & 0.25 & 0.09 & 0.18 & 0.03 & t & 0.05 \\
\hline $\begin{array}{lr}\text { Benz } & {[\mathrm{a}]} \\
\text { anthracene }\end{array}$ & 0.07 & 0.03 & 0.02 & 0.02 & V & 0.07 \\
\hline $\begin{array}{l}\text { Benzo }[\mathrm{b}] \\
\text { fluoranthene }\end{array}$ & 0.05 & t & 0.03 & t & 0.03 & V \\
\hline
\end{tabular}




\begin{tabular}{|c|c|c|c|c|c|c|}
\hline $\begin{array}{l}\text { Benzo [k] } \\
\text { fluorathene }\end{array}$ & 0.07 & 0.34 & 0.07 & 0.02 & 0.06 & 0.02 \\
\hline $\begin{array}{l}\text { Benzo [g,h,i] } \\
\text { perylene }\end{array}$ & 0.13 & 0.03 & I & f & f & 0.04 \\
\hline $\begin{array}{l}\text { Indeno }[1,2,3- \\
\text { cd] pyrene }\end{array}$ & 0.18 & V & I & f & $V$ & 0.01 \\
\hline $\begin{array}{l}\text { Dibenz [a,h] } \\
\text { anthracene }\end{array}$ & 0.16 & 0.07 & I & V & $V$ & \\
\hline$\sum$ PAHs & 1.40 & 3.87 & 0.90 & 0.85 & 0.63 & 0.69 \\
\hline
\end{tabular}

Jabrinder Singh, Naveen Singhal, Shailey Singhal, Madhu Sharma, Shilpa Agarwal, and Shefali Arora, (2017) ${ }^{[3]}$ describes the study of $\mathrm{NO}_{\mathrm{x}}, \mathrm{CH}_{4}, \mathrm{SPM}, \mathrm{CO}$, and $\mathrm{CO}_{2}$ emanation due to the blazing of Rice and Wheat leftover mainly in the northwestern states of India. Paper describes different methods that can be adopted for the management of crop stubble. Some of them are as follows:

\section{On-Farm Soil Mulching and Compost Production:}

The homestead buildup has the scope of discretionary qualities; nonetheless, farmers favor the burning of paddy as the easiest mode for removing the buildup. Motorized gathering, ranchers decide on in situ consolidations of the cultivated

buildup in the dirt. As indicated by the review, the favorable alternate for the blazing of paddy leftover is a mixture of soil on the field site. A few researchers detailed that the residue left, joining in the soil for 21 days before to develop impressively builds the residue of wheat on the dirt top layer of soil. It likewise builds up natural carbon concentration in soil by $14-29 \%$. Despite what might be expected, if the paddy buildup is amalgamated immediately before planting the wheat in rabi, at that point the harvest creation is decreased as of the capture of dormant nitrogen which antagonistically causes nitrogen deficiency. Various examinations demonstrated that probably the best technique to lessen this danger is the joining of straw into the dirt which ultimately improves soil ripeness.

\section{Alternate Methods of Crop Leftover Management:}

A portion of paddy residue can be used for animal feeding; fuel the material in power generation; use in shroom cultivation, for agricultural construction planning; Mash fabricating can be joined to keep away from the disadvantages of paddy and straw consuming. Some substitute use incorporates a mixture of paddy and wheat in the soil to deliver compost, different heat and energy innovations, and nuclear energy age. The yield buildup can also be used for manure and vermicompost development. These methods are received customarily likewise in different cultivating rehearses. An emerging step to forestall this danger is to establish liquor processing plants to make supportable energy form from the homestead product buildup by utilizing different ideas. Energy producing plants can additionally be used for the removal of harvest buildup, for example, straw and stubble.

Consuming of ranch buildups, for example, straw and stubbles from paddy-wheat cultivating frameworks of Punjab, Rajasthan, Haryana, and U.P. at a huge scope is a matter of the mound burden which brings about ozone harming substances discharge other than causing issues of climatic contamination, wellbeing dangers, and whipping supplements from the dirt. It turns into the need of great importance to verify the emanation estimations tentatively also, the unified equivocalness. The ranch yield buildups can be abused in different beneficial techniques, for example, manure development and digestion in soil, this is conceivable just if straw and paddy are assembled also, took tend of appropriately. Notwithstanding different severe enactment and 
consistence steps executed by the Administration of India and distinctive state specialists, this dangerous act of stubble consuming ceaselessly burdens to surrounding air aspect and wellbeing issues of territory and end up being a matter of mound burden in any event, for different modes of shipment. The powerful crucifixion of legal arrangement decisions to control this danger is needed with occasional to constant checking and improvement. As indicated by MoEFCC, the forbiddance of stubble consumption by conditions of Haryana, Punjab, UP, and Rajasthan have a result a 40 and $21.4 \%$ decrease in paddy consumption in Punjab and Haryana, separately. Projects identified with mindfulness and motivating forces should be dispatched for the cultivating networks. They will be well cognizant and analogous to the destructive results of harvest straw and stubble blazing and the meaning of substitute uses, for example, the use of the homestead stays in the dirt, for supporting rural proficiency.

\section{Zheng Fang, Wei Deng, Yanli Zhang, Xiang Ding, Mingjin Tang, Tengyu Liu, Jianmin Chen, Yele Sun, Christian Geroge, $(2017)^{[4]}$ describes the}

difficulties faced due to open burning in the country of China. Analysis of different catastrophic gases such as $\mathrm{NO}_{\mathrm{x}}, \mathrm{NH}_{3}, \mathrm{SO}_{2}, 67 \mathrm{NMHCs}$, particulate matter (PM), organic drizzle, and black carbon (BC). Globally, biomass blazing is the main cause of Organic, Black, and Brown Carbon. In the review various Instrumentation is discussed:

Various Instruments are helpful for the online observation of $\mathrm{NOx}, \mathrm{NH}_{3}$, and $\mathrm{SO}_{2} \cdot \mathrm{CH}_{4}$ and $\mathrm{CO}$ are analyzed by the help of Gas gas chromatography with flame ionization. For the measurement of the buoyant biological compound, a proton-transfer- reaction time-of-flight mass spectrometer is used, calibration of this device is done every two weeks using a standard mixture of VOCs. The amount of particle and size variations is done with a scanner. For the measurement of Black Carbon a sevenchannel aethalometer.

Data Analysis: The analysis is carried out by Particle potent frequency by the assumption that grains are nonporous as well as spherical and can be carried out by emission factors and modified ignition efficiency and Ozone formation potential, Wall loss Corrections, OA production prediction. In this examination, essential outflows of consuming rice, corn, and wheat residue and their photochemistry were examined in a huge closed chamber.

Naxieli Santiago-De La Rosa, Griselda Gonzalez, Jose de jesus, Figueora-Lara, Mirella Gutierrez- Arzaluz,...,Violeta Mugica-Alvar, (2018) ${ }^{[5]}$ describes and concentrates on the evaluation of radiation factors of P.M of sizes 2.5 and 10, Methane, $\mathrm{CO}_{2}$, Carbon Monoxide, EC and OC. The crops which are considered are cereals, Rice, Fodder, Maple, Beans, Grasp, Mace, and Alfalfa in Mexico. Emission factors are used to derive the emission from the above mentioned 8 crops, to know the capacity harm of them towards climate and atmospheric pollutants. These factors are not the same for all the crops, these differ according to the crop.

Collection of Agricultural Residue - The crop leftovers are taken from various parts of the country thus ensuring variability from other parts of the country. The transportation is done in bags and is dried in an open environment so that a moisture content from $6 \%$ to $13 \%$ can be maintained. Different researchers claimed that moisture content plays an important role in the analysis of residue properties and analyses.

Agricultural Waste Burning- Waste burning is done at open combustion chambers with a regulated oxygen supply. Over the ignition chamber, a chimney is constructed which helps to displace the particulate matter. The whole process of combustion is performed with a butane gas lighter.

10 tests are performed to find the optimum blazing condition and to avoid saturation.

Following combustion periods were seen for all 8 crops: 
Table-2: Comparison of different crops with respect to combustion periods.

\begin{tabular}{|l|l|l|}
\hline Crop & Weight in & Combustion \\
\hline & grams & $\begin{array}{l}\text { Period/time in } \\
\text { minutes }\end{array}$ \\
\hline Alfalfa & 600 & 5 \\
\hline Bean & 400 & 5 \\
\hline Barley & 600 & 3 \\
\hline Grasp & 400 & 5 \\
\hline Mace & 600 & 6 \\
\hline Sorghum & 400 & 4 \\
\hline Rice & 400 & 3 \\
\hline Cereal & 600 & 5 \\
\hline
\end{tabular}

The agricultural residue of Sorghum and grasp with more lignite content emit more emission factors. Black Carbon content was highest in cotton and was smallest in rice.

Dr. Jabrinder Singh,(2018) ${ }^{[6]}$ Describes the practice of paddy blazing and the major effect of this practice on the surrounding environment. Burning of farm leftover exhales various harmful gases that are $\mathrm{CO}_{2}, \mathrm{CO}, \mathrm{CH}_{4}$, Sulphur and a huge quantity of particulate matter. Crop residue is the left remaining after the cultivation of the crop. Farmers use different cultivation techniques the major and most easy to use is the Combined Harvestor. This machine separates the Grain and the fodder simultaneously. It saves a lot of time for the farmer which is the main concern as the time is limited between the harvesting of rice and the sowing of wheat. As this technique has this many advantages it also has a major disadvantage that is that this machine cultivates the crop from above a meter from the ground level

which lefts the leftover on the ground and because of time limitation consideration the farmers sets their field on fire and burn the leftover residue which becomes the main cause of this nuisance.

Status of Crop Residue burning in India- Several steps have been taken towards the north-western states not only Punjab and Haryana. This practice is reported in the state of Rajasthan, U.P, and New Delhi also. Haryana and Punjab governments began to implement a weighty punishment towards liable ranchers and state monitoring departments are using satellite symbolism and geographic information provided from a far-off detecting community to find the buildup consuming spots in the open country. Analysts and organizers have likewise started working in agreement to teach the ranchers on the protected removal of yield buildups and option practical ways for its utilization and ideal administration remembering its monetary qualities.

Figure -2: Satellite Images of paddy blazing in Punjab and nearby places.

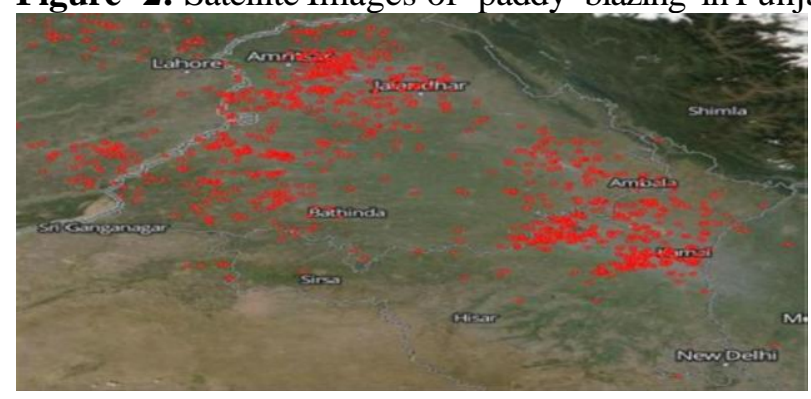

Management of crop stubble- Management of the residue left on the ground can be used in the feeding of animals, for small as well as large scale energy production with the help of methane gas. Composting can be done from the residue and can be used as compost in the soil which results in the increase of crop yield and also induces strength for the next coming crop season. This composting process is a time taking 
process and also needs more manpower. The best manageable step is to provide a market connection of farmers to the energy- producing industries which can act as a catalyst and which may provide the farmer the accurate use of the residue which in last would help in the management of crop residue burning.

Dinesh Kumar Saini, Vikas Kumar Singh, Anand Kumar, (2018) ${ }^{[7]}$ - Describes the problem of paddy blazing faced by the environment and also to farmers. This practice is only done due to time limitations between the rabi and Kharif crop. Modern agriculture equipment "known as Combined Harvesting System" do not completely cut the crop from the ground as a result a meter height of crop remains on the ground. For this problem the best economical way a farmer gets is to set the field on fire and which leads to all the problems as discussed before. Stubble is not completely a total waste, constituting about $25 \%$ nitrogen and phosphorus, $50 \%$ sulfur, and $75 \%$ potassium is retained in the residue, the burning decreases the nutrient present in them. So, clearly crop residue is not a waste but rather is a useful natural resource. In summary, burning leads to two impacts- First, the onsite impact which includes removal of large organic matter and loss of useful fauna and microflora. The second impact is the off-site impact which includes health- related hazards due to degraded air aspect and which leads to various harmful diseases like Bronchitis, Asthma, Cardiac problems, Eye irritation, and various other skin diseases.

Dipti Grover and Smita Chaudhry, (2019) ${ }^{[8]}$ - Describes the ground ambient air control before and after stubble burning at various locations in Haryana (Kaithal, Kurukshetra, and Karnal) for two successive years (2016 and 2017). The concentration of various pollutants like oxides of nitrogen, sulfur, and methane, etc. were determined along with Air Quality Index (AQI), for rice and wheat crops before and after burning periods. There was a notable increase noticed in the number of pollutants after and before the practice. An increase in Sox, NOx, and PM2.5 were observed. The overall pollutant concentration was found to be more in Karnal as compared to Kurukshetra and Kaithal. AQI was also degraded in the period of the study year. This shows that there is a need to stop this pollution caused by stubble burning and sustainable agricultural practice should be introduced. To combat this problem, the government and NGOs should help farmers in the fast transportation of the residue and should use this natural resource as a fuel for various power generation methods.

Hiren Jethva, Omar Torres, Robert D.Field, Alexei Lyapustin, Ritesh Gautam and Vinay Kayetha, (2019) ${ }^{[9]}$ - Describes the comparison of Vegetation Index and the post-harvesting burning.

The study a $25 \%$ increase in the Vegetation Index in Punjab. Vegetation Index is derived from MODIS Sensor onboard Satellite. The thermal Anomaly of MODIS revealed a rise of $60 \%$ in the fire activity and also increased disturbance invisibility in NCR Delhi. A 2014 report of WHO revealed that around 7 million decease 1 in 8 of total global decrease ratio were because of air pollution, and this practice of paddy blazing in India made cities in the Indo- Gangetic Plain consistently prone to high degrees of air pollution.

Crop Production Data- The rice production data was collected from the crop production statistics information system designed which is developed by the agriculture Informatics Department, National Informatics Hub, Ministry of Communication \& Information Technology, Government of India.

Ground-Level PM 2.5 Mearsurements- The US Embassy \& consulates operate PM2.5 measuring instrument, under the Air monitoring program in New Delhi.

Visibility data from NOAA's climate data center- Reports from this data center help in measuring the extinction coefficient (ßext) using the empirical Koschmeider relationship ßext=1.9/visibility, the visibility is measured inkilometers. 
Figure -3: (a) Satellite images showing fire activity (b) Annual variations in the production of rice.

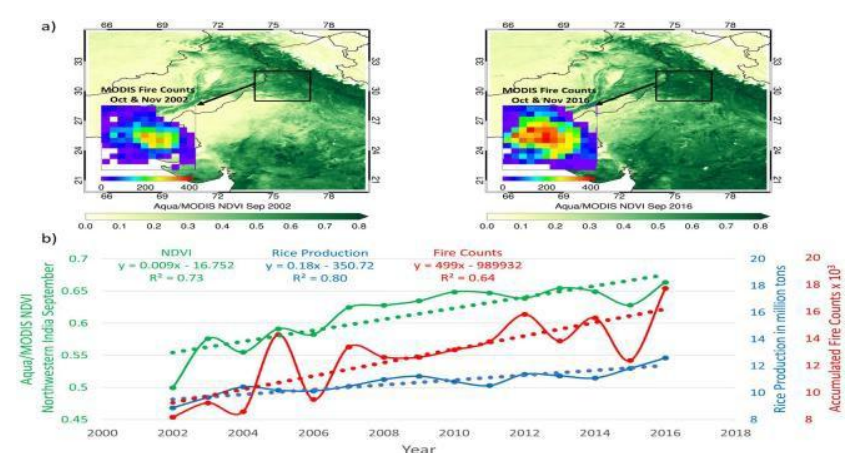

Sheetal Bhadauriya, Navendu Chaudhary, S. Mamatha and S.S. Ray,(2020) $)^{[10]}$ Describes the relationship between burning and the harmful effects on it to the environment. The study area taken includes Punjab and the nearby state of Haryana. The effect of Open firing of the paddy is viewed for the NCR region. Data collection for rice was done by (Ray \& Neetu, 2017). District wise collection of data was done for the year 2014 to 2017. Height of pollution was studied based on the properties of aerosols like (AOD), (SSA), and (AE). AOD is the measure of light that aerosol stops by adsorption and scattering. SSA is calculated by the ratio of total scattering to that of lost scattering. Meteorological entities like airspeeds and direction, temperature, and precipitation were downloaded from the Meteorological and Oceanographic Satellite Data Archival Center of ISRO.

\section{Conclusion}

The Farming practices in Indo-Gangetic Plains (IGP) in the state of Punjab and Haryana include the burning of crop leftover, as it less time consuming and economical method as seen by the farmer scenario. Large open scale burning of the residue leads to the emission of catastrophic gases causing atmospheric pollution, health hazards to humans, and also reduce the crop yield as it also affects the soil. Crop leftover is not a total waste as it comprises nutrients which make it suitable for the use in domestic animal fodder, Bioenergy generation, and also fuel for various power plants. Although various bans and laws are build-ups against the paddy blazing by the Government of India it is still prevailing in the states because farmers are not enlightened by the harmful effects of this practice on the surrounding.

Steps that can be initiated to reduce the crop residue burning:

- Extending activities and programs which educate farmers on the usefulness of the residue

- Enlightening the farmers about the effects and impacts of the practice.

- Making biomass and thermal industries act like as a catalyst by buying the residue from the farmer and for the further processing and by this farmer community would also get financial help. 


\section{References}

[1] Anu Rani Sharma, Sailesh Kumar Kharol, K.V.S. Badarinath, and Darshan Singh. (2009). Impact of Agricultural crop residue burning on atmospheric aerosol loading- a study over Punjab State, India. Annales Geophsicae,28,367-379.

[2] Zhang,H., Hu,D., Chen, J., Ye,X.,Wang,S.X., Hao, J.M.,..An, Z. (2011). Particle size distribution and polycyclic aromatic hydrocarbons emissions from agricultural crop residue burning. Environmental Science \& Technology,45(13), 5477-5482.

[3] Jabrinder Singh, Naveen Singhal, Shailey Singhal, Madhu Sharma, Shilpi Agarwal and Shefali Arora.(2017). Environmental Implications of Rice and Wheat Stubble burning in North-Western States of India. J. Singh et al. 47-55.

[4] Zheng Fang, Wei Deng, Yanli Zhang,....Yele sun, Christan George.(2017). Open burning of rice, corn and wheat straws: Primary Emissions, photochemical aging, and secondary organic aerosol formation. Atmospheric Chemistry and Physics, 17,14821-14839.

[5] Naxieli Santiago-De La Rosa, Griselda Gonzalez-Cardoso, Jose de jesus, Figueroa-Lara, Mirella Gutierrez-Arzaluz,...,Violeta Mugica-Alvar.(2018). Emission factors of atmospheric and climate pollutants from crop residue burning. Journal of the Air and Waste Management Association. Vol. 68, No.8,849-865.

[6] Dr. Jabrinder Singh.(2018).Paddy and wheat stubble blazing in Haryana and Punjab states of India: A menace for environmental health. Environ Qual Manage, 1-7.

[7] Dinesh Kumar Saini, Vikas Kumar Singh, Anand Kumar.(2018). Stubble burning: either farmers to be punished or technology need to be improved?, Biomolecule Reports. Saini et al., BR/09/18/04.

[8] Dipti Grover and Smita Chaudhry.(2019).Ambient air quality changes after stubble burning in rice- wheat system in an agricultural state of India. Environmental Science and Pollution Research 26:20550-20559.

[9] Hiren Jethva, Omar Torres, Robert D. Field, Alexei Lyapustin, Ritesh Gautam and Vinay Kayetha.(2019). Connecting Crop Productivity, Residues Fires and Air Quality over Nothern India. Sceintific Reports. 9;16594,1-11

[10] Sheetal Bhadauriya, Navendu Chaudhary, S.Mamatha and S.S. Ray.(2020). Relationship between Rice residue burning and increasing air pollution in North-west India. The international archives of the photogrammetry, Remote sensing and spatial information sciences.XLIII-B3-20202,1423-1430. 